\title{
Efficacy of Vitamin E Treatment for Hand-Foot Syndrome in Patients Receiving Capecitabine
}

\author{
Daigo Yamamoto Chizuko Yamamoto $^{\mathrm{b}}$ Satoru Iwase $^{\mathrm{c}}$ \\ Yujiro Kurodac ${ }^{c}$ Hiroki Odagiri $^{\mathrm{d}}$ Yoshinori Nagumo $^{\mathrm{e}}$
}

${ }^{a}$ Department of Surgery, Kansai Medical University, Hirakata, Osaka, 'Department of Internal Medicine, Seiko Hospital, Neyagawa, Osaka, 'Department of Palliative Medicine, University of Tokyo Hospital, Tokyo, 'Department of Surgery, Hirosaki University, Hirosaki, Aomori,

${ }^{\mathrm{e} B r e a s t}$ Unit, Nagumo Clinic, Tokyo, Japan

Capecitabine is a novel oral fluoropyrimidine that is converted within tumor cells to fluorouracil by thymidine phosphorylase [1]. Hand-foot syndrome (HFS) is the most frequent side effect of capecitabine and has been reported in up to $71 \%$ of patients receiving a starting dose of $1,250 \mathrm{mg} / \mathrm{m}^{2}$ twice daily [2-7]. Grade 3 HFS was reported in up to $10-24 \%$ of patients. Treatment interruption and, if required, dose reduction usually ameliorate symptoms without compromising efficacy $[8,9]$. Supportive treatments such as topical wound care, elevation, and cold compresses may help to relieve pain $[10,11]$. Use of systemic corticosteroids, pyridoxine (vitamin B6), and cox-2 inhibitors have been used in patients developing HFS with cytotoxic agents including capecitabine and pegylated liposomal doxorubicin with varying success [11-13]. Kara et al. [13] from Turkey reported apparent benefit of vitamin $\mathrm{E}$ in managing HFS. Therefore we conducted this study to examine the efficacy of vitamin $\mathrm{E}$ in managing capecitabine-induced HFS.

This retrospective, multicenter study was undertaken between 2005 and 2009 in HER2-negative patients with breast cancer treated with oral capecitabine $828 \mathrm{mg} / \mathrm{m}^{2}$ twice daily on days 1-21 every 4 weeks. Patients with symptoms of grade 2 HFS received oral vitamin E (Tocopherol Acetate, Eisai Pharmaceuticals, Tokyo, Japan) $100 \mathrm{mg} /$ day without chemotherapy dose modification. Patient and treatment-related data, e.g. chemotherapy-related toxicities, dose of vitamin E, severity of symptoms, and tumor response to therapy, were recorded every 4 weeks. Patients underwent a complete dermatological examination at every visit. HFS including pain was graded using the National Cancer Institute Common Terminology Criteria for Adverse Events version 3.0 (NCI-CTCAE v3.0). Wilcoxon signed rank test was used to examine patient demographics and treatment information. Median time to onset of grade 2 HFS was estimated. Severity of HFS was compared before and after vitamin $\mathrm{E}$ administration. We identified 32 patients developing grade 2 HFS during capecitabine therapy between January 2005 and February 2009, who subsequently received vitamin $\mathrm{E}$ with or without capecitabine treatment modification. The median time to first onset of HFS was 7.3 months (range 4.1-9.6). The initial starting dose of vitamin E for treatment of HFS was $100 \mathrm{mg} /$ day, and the median dose of vitamin E was $200 \mathrm{mg}$ (range 100-400 $\mathrm{mg}$ /day). Vitamin E application had a marked effect on dermatological complications within 7 days of initiation. The effect lasted throughout administration. Desquamation and pain reduced gradually (figs. 1 and 2), and the comfort level of the patients improved. Fifteen of 32 patients (46.9\%) with HFS experienced symptom improvement with vitamin E (100 $\mathrm{mg} /$ day) ( $\mathrm{p}<0.05$; before vs. after 2 months vitamin $\mathrm{E}$ administration). Neurological symptoms improved. Thirteen patients still had pain, but this decreased after vitamin $\mathrm{E}$ dose escalation to $400 \mathrm{mg} /$ day. The remaining 4 patients had considerable pain interfering with function after vitamin E 100 $\mathrm{mg} /$ day, but this reduced after vitamin $\mathrm{E}$ dose escalation to $400 \mathrm{mg} /$ day and dose reduction of capecitabine as described previously [14]. Among all 32 patients included, the overall response rate to capecitabine was $37.5 \%$, comprising 2 complete and 10 partial responses. Patients receiving capecitabine and vitamin E (100-400 mg) had longer time to progression than did patients receiving dose reduction of capecitabine (median 10.2 months vs. 6.1 months).

In this retrospective study, 15 of 32 patients with HFS improved with vitamin E $100 \mathrm{mg} /$ day, suggesting a beneficial effect of vitamin E therapy. Vitamin $E$ is a widely used skin care product and functions as the major lipophilic antioxidant, preventing peroxidation of lipids and resulting in more stable cell membranes. The antioxidant membrane stabilizing effect of vitamin $\mathrm{E}$ also includes stabilization of the lysomal membrane, a function shared with glucocorticoids [13]. Systemic vitamin $\mathrm{E}$ and glucocorticoids inhibit the inflammatory response and collagen synthesis, thereby possibly impeding the

\section{KARGER}

Fax +497614520714

Information@Karger.de

www.karger.com (c) 2010 S. Karger GmbH, Freiburg

Accessible online at:

www.karger.com/brc
Daigo Yamamoto, M. D

Department of Surgery

Kansai Medical University

Hirakata, Osaka 570-8507, Japan

Tel. +81 72 80401-01, Fax -70

yamamotd@hirakata.kmu.ac.jp 


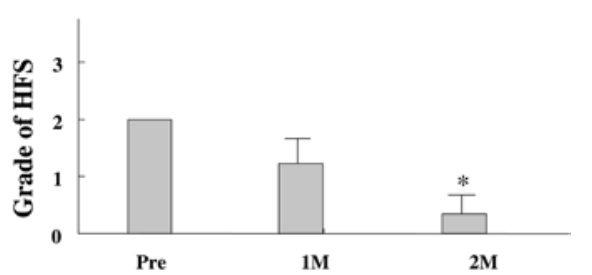

Fig. 1. Hand-foot syndrome (HFS) began to disappear after 1 month of vitamin $\mathrm{E}$ treatment; 15 of 32 patients ( $47 \%$ ) with HFS experienced symptom improvement with vitamin $\mathrm{E}$ $(100 \mathrm{mg} /$ day $)(\mathrm{p}<0.05)$.
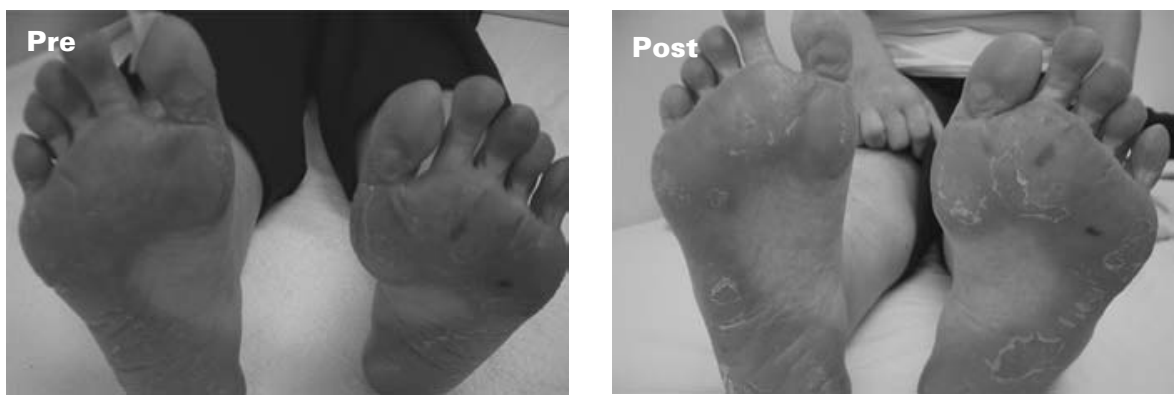

Fig. 2. Clinical presentation of hand-foot syndrome. After vitamin $E$ without dose reduction of capecitabine, the skin lesions had disappeared. healing process. Therefore the use of vitamin E may be useful for patients with HFS. The mechanism of HFS is unclear and may vary among the different agents associated with this effect [15-17]. In patients receiving capecitabine, HFS is dosedependent and probably related to accumulation of drug and/ or metabolites in the skin. It has been suggested that capecitabine-induced HFS may result from increased concentrations of the enzyme thymidine phosphorylase (TP) in specialized skin cells [18]. TP plays a crucial role in the activation of capecitabine and thus this localization in the skin cells may explain capecitabine metabolite accumulation, resulting in HFS. Alternatively, a recent study showed that the high proliferation rate of epidermal basal cells in the palm could make them more sensitive to local action of 5-fluorouracil, thus contributing to the occurrence of HFS [19]. While our observations and the potential role of vitamin $\mathrm{E}$ deserve further investigation, patient education and good follow-up during capecitabine therapy remain the cornerstones of management. Early recognition is critical to the effective management of HFS. When patients are appropriately managed, they will receive maximum benefit from this agent. Vitamin E-containing preparations appear to offer some benefit as an adjunctive approach for the treatment of capecitabine-induced HFS.

\section{Acknowledgment}

The authors are indebted to Mr. Nishikawa in Chugai Pharmaceutical Co., Ltd.

\section{Conflict of Interest}

The authors declare no conflict of interests.

\section{References}

1 Miwa M, Ura M, Nishida M, Sawada N, Ishikawa T, Mori K, Shimma N, Umeda I, Ishitsuka H: Design of a novel oral fluoropyrimidine carbamate, capecitabine, which generates 5-fluorouracil selectively in tumours by enzymes concentrated in human liver and cancer tissue. Eur J Cancer 1998;34:1274-81.

2 Fumoleau P, Largillier R, Clippe C: Multicentre, phase II study evaluating capecitabine monotherapy in patients with anthracycline- and taxanepretreated metastatic breast cancer. Eur J Cancer 2004:40:536-42.

$\checkmark 3$ Blum JL, Jones SE, Buzdar AU: Multicenter phase II study of capecitabine in paclitaxel-refractory metastatic breast cancer. J Clin Oncol 1999;17:485-93.

4 Blum JL, Dieras V, Lo Russo PM: Multicenter, phase II study of capecitabine in taxane-pretreated metastatic breast carcinoma patients. Cancer 2001a;92:1759-68.

5 Reichardt P, von Minckwitz G, Thuss-Patience PC: Multicenter phase II study of oral capecitabine (Xeloda(")) in patients with metastatic breast cancer relapsing after treatment with a taxane-containing therapy. Ann Oncol 2003;14:1227-33.

$\checkmark 6$ Miller KD, Chap LI, Holmes FA, Cobleigh MA, Marcom PK, Fehrenbacher L, Dickler M, Overmoyer BA, Reimann JD, Sing AP, Langmuir V, Rugo HS: Randomized phase III trial of capecitabine com- pared with bevacizumab plus capecitabine in patients with previously treated metastatic breast cancer. J Clin Oncol 2005;23:792-9.

7 Stockler MR, Sourjina T, Grimison P: A randomized trial of capecitabine (C) given intermittently (IC) rather than continuously (CC) compared to classical CMF as first-line chemotherapy for advanced breast cancer (ABC). J Clin Oncol 2007;25:1031.

8 Blum JL, Jones SE, Buzdar AU; on behalf of the Xeloda Breast Cancer Study Group: Capecitabine in 162 patients with paclitaxel-pretreated MBC: updated results and analysis of dose modification. Eur J Cancer 2001;37(suppl 6):190(abstr 693).

$\checkmark 9$ Leonard R, O'Shaughnessy J, Vukelja S: Detailed analysis of a randomized phase III trial: can the tolerability of capecitabine plus docetaxel be improved without compromising its survival advantage? Ann Oncol 2006;17:1379-85.

10 Frye DK: Capecitabine-based combination therapy for breast cancer: implications for nurses. Oncol Nurs Forum 2009;36:105-13.

11 Gressett SM, Stanford BL, Hardwicke F: Management of hand-foot syndrome induced by capecitabine. J Oncol Pharm Pract 2006;12:131-41.

12 LassereY, Hoff P: Management of hand-foot syndrome in patients treated with capecitabine (Xeloda). Eur J Oncol Nursing 2004;8:S31-40.
13 Kara IO, Sahin B, Erkisi M: Palmar-plantar erythrodysesthesia due to docetaxel-capecitabine therapy is treated with vitamin $\mathrm{E}$ without dose reduction. Breast 2006;15:414-24.

14 Yamamoto D, Iwase S, Kitamura K, Odagiri H, Yamamoto C, Nagumo Y: A phase II study of trastuzumab and capecitabine for patients with HER2-overexpressing metastatic breast cancer: Japan Breast Cancer Research Network (JBCRN) 00 Trial. Cancer Chemother Pharmacol 2008;61: 509-14.

15 Haller DG, Cassidy J, Clarke SJ: Potential regional differences for the tolerability profiles of fluoropyrimidines. J Clin Oncol 2008;2:2118-23.

16 Halliwell B, Gutteridge JMC: Free Radicals in Biology and Medicine. Oxford, Oxford University Press, 1993, pp. 188-276.

17 Lacouture ME, Wu S, Robert C: Evolving strategies for the management of hand-foot skin reaction associated with the multitargeted kinase inhibitors sorafenib and sunitinib. Oncologist 2008;13:1001-11.

18 Asgari MM, Haggerty JG, McNiff JM: Expression and localization of thymidine phosphorylase/ platelet-derived endothelial cell growth factor in skin and cutaneous tumors. J Cutaneous Pathol 1999;26:287-94.

19 Milano G, Etienne-Grimaldi M-C, Mari M: Candidate mechanisms of capecitabine-related hand-foot syndrome. Br J Clin Pharmacol 2008;1-8. 